\title{
Aplikasi Pemesanan Multi Catering Berbasis Android
}

\author{
Tommy Chandra Pangestu, Departemen Informatika, Institut Sains dan Teknologi Terpadu Surabaya, \\ Amelia Alexandra P. W., Departemen Informatika, Institut Sains dan Teknologi Terpadu Surabaya, \\ dan Tjwanda Putera Gunawan, Departemen Informatika, Institut Sains dan Teknologi Terpadu \\ Surabaya
}

\begin{abstract}
Abstrak-Pihak catering ingin mempertahankan dan menambah customer dengan menyajikan pilihan menu yang bervariasi. Sementara pihak customer sering berganti catering agar tidak bosan dengan makanan dari catering tertentu. Proses pemesanan kebanyakan catering yang ada sekarang, informasi yang diberikan kurang detail hanya sekedar melalui telepon, sehingga sering terjadi salah paham dalam pemesanan. Apalagi jika pada saat itu orang yang memesan catering sangat membutuhkan jasa catering tersebut. Untuk menjembatani hal ini, maka dibutuhkan sebuah aplikasi yang dapat menangani semua permasalahan dan meningkatkan kualitas layanan catering tersebut, yaitu aplikasi multi catering. Pada penelitian ini, dikembangkan aplikasi jasa layanan Multi Catering Online untuk usaha catering rumahan. Aplikasi ini berbasis android dilengkapi dengan web service PHP dan menyimpan data ke dalam database MySQL. Aplikasi Multi Catering ini hanya melayani bisnis catering rumahan, tidak melayani bisnis catering yang berbasis bisnis atau event. Terdapat 4 (empat) actor yang terlibat dalam aplikasi Multi Catering ini, yaitu admin aplikasi, vendor, pengantar, dan customer. Admin Multi Catering dapat memantau aplikasi Multi Catering seperti laporan, filter search, dan pengaturan member. Sedangkan, vendor catering merupakan pihak yang menyediakan catering yang hendak dipilih oleh customer pada aplikasi ini, baik paket maupun non paket. Pengantar merupakan user yang bertugas mengirimkan catering kepada customer yang memesan. Customer pada aplikasi ini merupakan user yang berperan sebagai pemesan catering. Dengan adanya aplikasi Multi Catering ini dapat membantu pihak vendor catering serta customer agar lebih mudah menangani proses pemesanan catering yang ada, dan meningkatkan layanan bisnis catering yang ada saat ini dengan bantuan chatting dan notifikasi. Aplikasi Multi Catering ini sangat menguntungkan vendor dan customer.
\end{abstract}

Kata Kunci-Android, Catering Online, Multi Catering, Web Service.

\section{Pendahuluan}

$\mathrm{B}$ isnis Catering selama ini hanya mengandalkan promosi dari mulut ke mulut dari kenalan sendiri, atau

Tommy Chandra Pangestu, Departemen Teknik Informatika, Sekolah Tinggi Teknik Surabaya, Jawa Timur, Indonesia (email: tommycp8@gmail.com)

Amelia Alexandra P. W., Departemen Teknik Informatika, Sekolah Tinggi Teknik Surabaya, Surabaya, Jawa Timur, Indonesia (e-mail: sandra@stts.edu)

Tjwanda Putera Gunawan., Departemen Teknik Informatika, Sekolah Tinggi Teknik Surabaya, Surabaya, Jawa Timur, Indonesia (e-mail: tjwanda@stts.edu) pemesanan melalui brosur kepada calon pelanggan. Begitu juga mengenai pemesanan, selama ini cara memesan makanan

masih menggunakan media telepon atau harus datang langsung ke lokasi catering, cara tersebut kurang efektif dan cepat, karena sering terjadi kesalahan dalam proses pemesanan makanan.

Berdasarkan permasalahan tersebut, maka Penelitian ini berfokus pada pemecahan untuk pengelolaan bisnis catering, dengan pengembangan Aplikasi Pemesanan Multi Catering Berbasis Android. Sistem ini dirancang untuk menangani multi catering (beberapa catering sekaligus). Pada aplikasi ini akan terdaftar beberapa vendor catering yang akan memasang paket menu yang berbeda untuk memudahkan marketing, serta memudahkan pelanggan dalam membandingkan harga paket menu yang akan dipilih dari berbagai vendor catering

\section{TEORI DASAR}

Teori dasar yang digunakan untuk kepentingan penelitian pada pembuatan aplikasi pemesanan multi catering berbasis Android ini meliputi web service, Firebase, Android, dan Google Map, Facebook API, Google API.

\section{A. Web Service}

Permasalahan yang membutuhkan web service adalah bagaimana membagi data diantara perangkat-perangkat yang ada dalam suatu jaringan yang luas. Hubungan antara client dan server dijembatani oleh file web service dalam format tertentu. Sehingga, akses terhadap database akan ditangani tidak secara langsung oleh server, melainkan melalui perantara yang disebut sebagai web service. Peran dari web service ini akan mempermudah distribusi sekaligus integrasi database yang tersebar di beberapa server sekaligus.

\section{B. Android}

Android pertama kali dikembangkan oleh perusahaan bernama Android Inc., dan pada tahun 2005 diakuisisi oleh raksasa Internet Google. Android memiliki komunitas developer yang besar untuk pengembangan aplikasi, ini membuat fungsi Android menjadi lebih luas dan beragam [5]. Android Market (sekarang Google Play) merupakan tempat download aplikasi Android baik gratis ataupun berbayar yang dikelola oleh Google. Android Studio adalah Lingkungan Pengembangan Terpadu-Integrated 


\section{JOURNAL OF INFORMATION SYSTEM, GRAPHICS, HOSPITALITY AND TECHNOLOGY}

Development Environment (IDE) untuk pengembangan aplikasi Android.[3]

\section{Firebase}

Firebase Realtime Database memungkinkan membuat aplikasi kolaboratif dan kaya fitur dengan menyediakan akses yang aman ke database, langsung dari kode sisi klien [2]. Firebase Realtime Database memungkinkan membuat aplikasi kolaboratif dan kaya fitur dengan menyediakan akses yang aman ke database, langsung dari kode sisi klien. Data disimpan di drive lokal, bahkan saat offline sekalipun, peristiwa realtime terus berlangsung, sehingga pengguna akan merasakan pengalaman yang responsif.

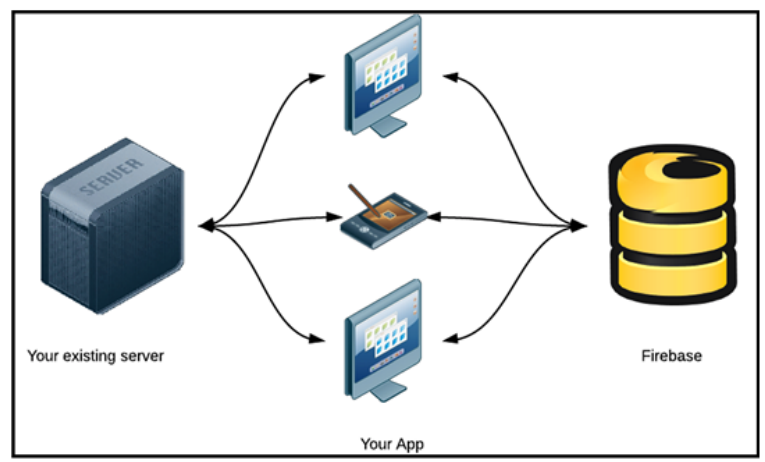

Gambar. 1. Arsitektur Firebase

Gambar 1 merupakan gambar arsitektur Firebase. Firebse menerima data dari aplikasi yang digunakan sesuai dengan servernya. Realtime Database adalah database NoSQL, sehingga memiliki pengoptimalan dan fungsionalitas yang berbeda dengan database terkait [4]. API Realtime Database dirancang agar hanya mengizinkan operasi yang dapat dijalankan dengan cepat.

\section{Google Maps API}

Google Maps API adalah fungsi-fungsi pemrograman yang disediakan oleh Google Maps, agar Google Maps bisa diintegrasikan ke dalam Web atau aplikasi yang sedang dibuat. Google Maps API adalah library JavaScript. Google Maps API bisa membuat GIS tanpa perlu memikirkan Peta Jogja, tinggal menggunakan Google Maps dan memanggil fungsi-fungsi yang dibutuhkan seperti menampilkan peta, menempatkan marker dan sabagainya.

\section{E. Facebook API}

Facebook API adalah platform untuk membangun aplikasi yang tersedia bagi anggota jejaring sosial Facebook. API memungkinkan aplikasi untuk menggunakan koneksi sosial dan informasi profil untuk membuat aplikasi lebih melibatkan, dan mempublikasikan aktivitas ke feed berita dan halaman profil Facebook, sesuai dengan pengaturan privasi pengguna individual.

\section{ANALISA SISTEM}

Analisa system meliputi penentuan kebutuhan system [1] sehimgga dapat mengatasi permasalahan yang ada. Permasalahan sering terjadi dalam bisnis catering yang sifat pencatatannya secara manual. Pencatatan secara manual ini terkadang juga terjadi kesalahan, karena dalam setiap pelayanan harus mengubah status pada buku pencatatannya. Customer terkadang bisa membatalkan pesanan dengan menelpon maksimal dua hari sebelumnya, maka pemilik catering harus mencari kertas pemesanan customer yang membatalkan serta mencoret catatan pemesanannya. Customer juga terkadang mengkomplain makanan karena tidak sesuai dengan permintaan. Pemilik catering sering kebingungan dalam mengatasi pelayanan terhadap customer, mengingat pada jasa catering pelayanan menentukan kepuasan dari pihak customer untuk bisa menjadi pelanggan tetap catering tersebut.

Selain masalah pencatatan dalam pelayanan, dari sisi customer catering, terkadang juga ingin makanan dari catering yang berbeda, sehingga tidak bosan dengan menu masakan yang berulang. Customer berkeinginan bisa memilih masakan dari beragam catering yang bisa diatur dengan mudah. Customer ingin bebas memilih masakan sesuai dengan kebutuhan dan selera Customer. Untuk mengatasi hal tersebut dan didukung oleh kemajuan teknologi komunikasi mobile, pada penelitian ini akan dibuat aplikasi Multi Catering berbasis Android

Untuk menampung proses pemesanan dan pengiriman pada beberapa catering yang informasinya sudah didapat saat melakukan analisa dan untuk memberikan kemudahan layanan pada customer dalam memilih catering agar tidak bosan dengan rasa serta memberikan kemudahan transaksi pada saat pembayaran dan pembatalan pemesanan, maka pada sistem multi catering ini dibutuhkan aplikasi yang bisa menjembatani keinginan dari vendor catering dan customer. Aplikasi dibuat berbasis Android memandang pengguna smartphone yang sudah umum digunakan oleh berbagai kalangan. Aplikasi yang menangani banyak catering ini disebut aplikasi multicatering yang mempunyai fasilitas untuk vendor catering bisa mengatur menu, paket menu, pengiriman catering, melihat pembayaran, melihat pembatalan, chatting dengan pengantar dan customer, mereport customer yang kurang sopan, dan withdraw saldo. Untuk pengantar pada aplikasi multicatering dibutuhkan fasilitas melihat list pesanan yang harus diantar oleh pengantar, GPS untuk membantu mencari alamat dan chatting dengan vendor dan customer. Untuk customer pada aplikasi multicatering dibutuhkan fasilitas memilih catering beserta menu dan paket menu yang ditawarkan oleh setiap catering, melakukan proses pemesanan, melakukan proses pembayaran dan top up, memberikan rating terhadap catering, chatting dengan vendor ataupun pengantar, mereport vendor dan menu, dan melihat laporan pemesanan catering. Untuk mengatur jalannya aplikasi supaya berjalan dengan lancar dibutuhkan seorang admin yang membutuhkan fasilitas pengaturan kategori makanan, pengaturan cita rasa, pengaturan bahan dasar, pengaturan member, pengaturan top up dan verifikasi withdraw dan pengaturan laporan.

\section{A. Fitur Admin Multi Catering}

Yang dimaksud dengan admin adalah admin dari pihak aplikasi Multi Catering yang bertanggung jawab penuh terhadap proses administrasi terutama terkait dengan uang dan kebijakan. Adapun fasilitas dari Admin Multi Catering 
dapat dijabarkan sebagai berikut:

- Master Member Digunakan untuk mengatur semua member yang terdaftar

- Verifikasi Top-Up

Memverifikasi top-up E-Money dengan mengecek bukti transfer dan apakah telah masuk ke dalam rekening.

- Verifikasi Withdraw Menguangkan E-Money vendor catering maupun pelanggan. Proses verifikasi dilakukan oleh admin selaku pengatur aplikasi Multi Catering.

- Verifikasi User

Menverifikasi user yang melakukan registrasi baik vendor catering maupun member pelanggan

- Master kategori, master bahan dasar, cita rasa

- Laporan Vendor Catering Terlaris, Laporan Pemasukan dan keluar top up, dan Laporan Report

- Setting

\section{B. Fitur Vendor Multi Catering}

Vendor adalah pihak-pihak yang bekerjasama dengan pihak Multi Catering. Dalam hal ini, vendor yang bekerja sama diwajibkan menyediakan jasa catering yang memiliki berbagai macam pilihan paket. Adapun fasilitas dari Vendor Multi Catering dapat dijabarkan sebagai berikut:

- Tambah/Ubah Menu

Vendor catering dapat menambah atau mengubah harga dan jenis perhari.

- List Pesanan

Setiap vendor catering akan diberikan sebuah list pesanan yang berisi pesanan yang dilakukan oleh setiap pelanggan.

- Plotting pengantaran

Mengatur siapa yang akan mengantarkan pesanan

\section{Fitur Pengantar Multi Catering}

Pengantar adalah user yang berperan sebagai pengantar untuk setiap vendor catering yang sudah terdaftar. Vendor catering wajib melakukan registrasi untuk setiap pengantar yang dimiliki. Adapun fitur yang dimiliki akan dijabar sebagai berikut:

- Mengantarkan Menu

Pengantar dapat melihat list pelanggan beserta menu yang harus diantar.

\section{Fitur Pelanggan Multi Catering}

Pelanggan adalah user yang memiliki peran untuk memesan catering pada aplikasi Multi Catering. Adapun fitur yang dimiliki akan dijabar sebagai berikut:

- Order Catering

Pelanggan dapat melakukan order sesuai dengan pesanan yang diinginkan

- Cancel Order

Pelanggan dapat melakukan cancel order maksimal 1 hari sebelum tanggal pengiriman

- List Order Pelanggan dapat melihat order yang sedang aktif

- Login with Facebook or Google Signin

Pelanggan dapat menggunakan fitur Google dan Facebook Login sebagai alternative untuk masuk dalam aplikasi multi catering.

\section{DESAIN SISTEM DAN IMPLEMENTASI}

Desain yang dijelaskan akan dibahas mulai dari desain arsitektural yang terdiri dari rich sistem yang tampak pada gambar 2. Jika user login sebagai role admin, maka data yang dikirim berupa data master, filter dan kata kunci, block unblock member, serta status top up dan withdraw. Kemudian data ini akan diteruskan melalui internet yang selanjutnya diteruskan kepada web service untuk diproses permintaan data yang diminta user admin tersebut. Setelah proses pada web service selesai, maka akan dilakukan pengecekan ke dalam database menggunakan query tertentu untuk mengakses data yang berada di server. Apakah data yang di-request ada di dalam database atau tidak. Jika data ada, maka data akan dikembalikan dan ditangani oleh web service lagi sebagai result data. Setelah itu, web service akan mengembalikan datanya berupa JSON output ke internet. Dari internet akan meneruskan output JSON tersebut ke mobile device user admin. Output yang dikeluarkan ke user admin dapat berupa tampilan laporan member, data pesanan, laporan top up dan withdraw.

User vendor juga memiliki alur yang serupa, tetapi tidak sama. Data yang dikirimkan oleh user vendor berupa data pengiriman, filter dan kata kunci, nominal withdraw, dan data pemesanan. Data tersebut dikirimkan dari mobile device ke internet. Setelah itu, internet akan mengirimkan data tersebut ke web service untuk dikelola datanya sesuai dengan permintaan user. Web service kemudian melakukan pengecekan data ke dalam database, jika data sesuai maka data akan dikirimkan dari database dan akan diproses oleh web service. Data dari database yang telah selesai diproses oleh web service akan keluar berupa output JSON. JSON output ini akan dikirimkan oleh web service melalui internet ke mobile device user vendor. Mobile device akan memproses JSON output ini dan merubah menjadi tampilan yang dapat dipahami oleh user vendor. Output yang diterima oleh user vendor dapat berupa tampilan laporan withdraw, laporan pemesanan, data pemesanan, dan status pengiriman.

Apabila user login sebagai role customer, maka data yang dikirimkan berupa data pemesanan, filter dan kata kunci, rating, menu direport, rating, dan nominal top up. Kemudian data tersebut akan dikirimkan oleh mobile device ke internet. Internet akan meneruskan data yang di request oleh user customer untuk diproses pada web service. Web service akan melakukan pengecekan dan memproses data ke dalam database, jika data yang di request pada database sesuai dengan permintaan user, maka data akan dikembalikan dan diproses kembali kepada web service. Web service akan memproses data dari database dan mengeluarkannya berupa JSON output. JSON output ini akan dikirimkan ke mobile decive user customer menggunakan internet. Mobile device user customer akan memproses JSON output menjadi tampilan yang dapat dipahami oleh user customer. Data output yang diterima oleh user customer dapat berupa tampilan laporan pemesanan, laporan top up dan data pemesanan. 


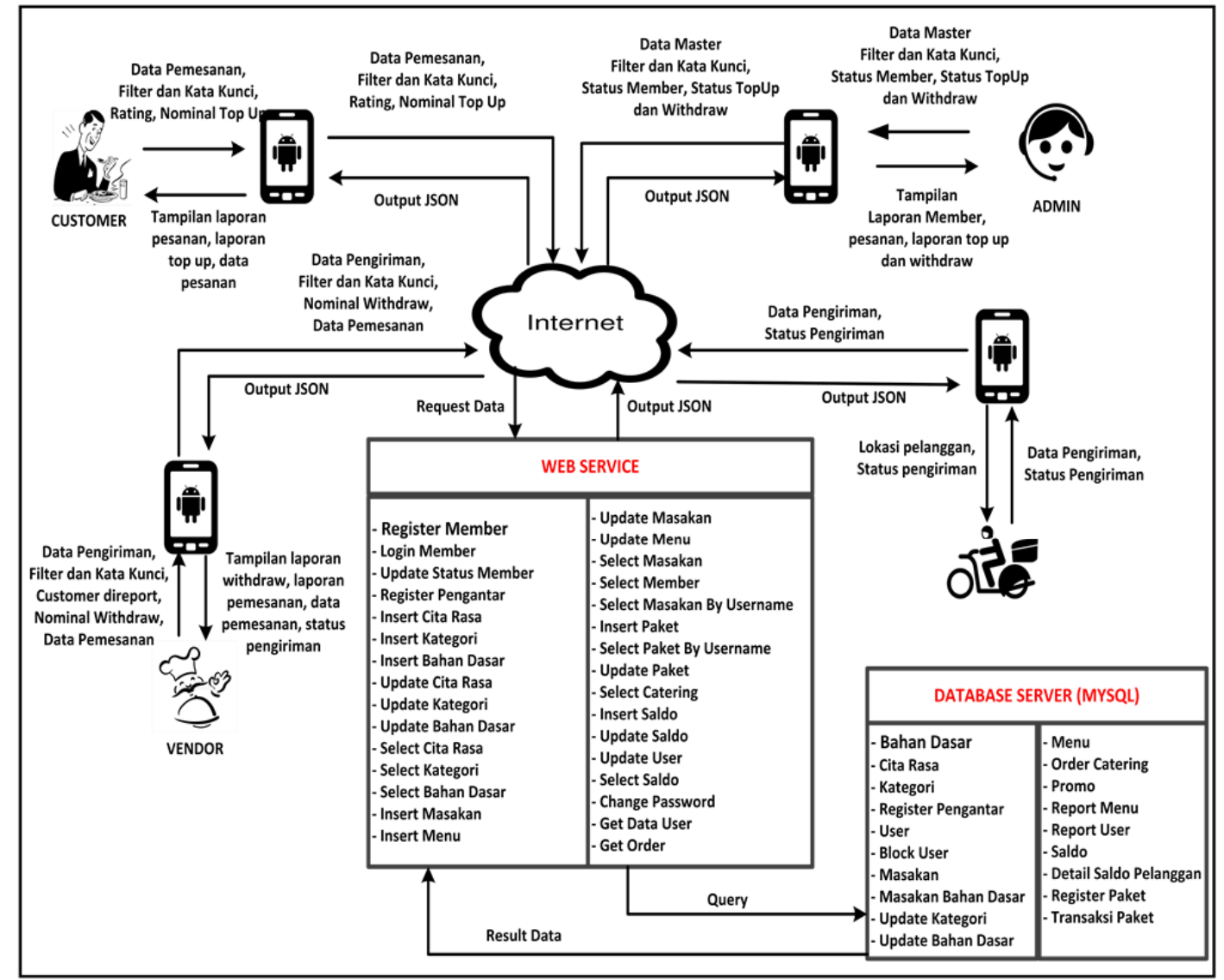

Gambar. 2. Arsitektur Sistem Multi Catering

Sedangkan jika user login sebagai role pengantar, maka data yang dikirimkan berupa data pengiriman dan status pengiriman. Data ini akan dikirimkan oleh mobile device ke internet. Kemudian internet akan meneruskan data tersebut kepada web service. Web service sendiri akan memproses data yang di request oleh user pengantar dan melakukan pengecekan ke dalam database. Apabila data yang di request sesuai dengan yang ada pada database, maka data akan dikembalikan untuk diproses ulang kepada web service. Setelah web service selesai memproses data dari database, maka data akan keluar berupa JSON output. Web service kemudian akan mengirimkan JSON ouput tersebut kepada internet. Setelah itu internet akan meneruskan JSON output kepada mobile device user pengantar. Mobile device user pengantar akan memproses JSON output ini agar dapat diubah menjadi tampilan yang dapat dipahami oleh user pengantar. Output untuk user pengantar adalah data tampilan data lokasi pelanggan dan status pengiriman

\section{A. Desain Database}

Desain database pada sistem multi catering ini dapat dilihat pada gambar 3 .

\section{B. Desain Interface}

Desain interface pada aplikasi multicatering ini dapat dicontohkan pada gambar-gambar berikut yaitu setting customer, detail menu, laporan

Apabila user telah memilih catering yang memiliki sistem penjualan non paket. Tampilan list menu memberikan keterangan seputar nama menu dan harga menu yang telah didaftarkan oleh vendor catering pada aplikasi multi catering. Jika user telah selesai menentukan menu apa yang ingin dipesan, maka user dapat menekan menu yang diinginkan tersebut, maka user akan langsung diarahkan ke halaman detail menu. Pada halaman ini terdapat beberapa inputan yang harus diisi, seperti tanggal kirim, request jam kirim, keterangan pada pihak catering apabila ingin merequest sesuatu, serta jumlah menu yang ingin dipesan. 


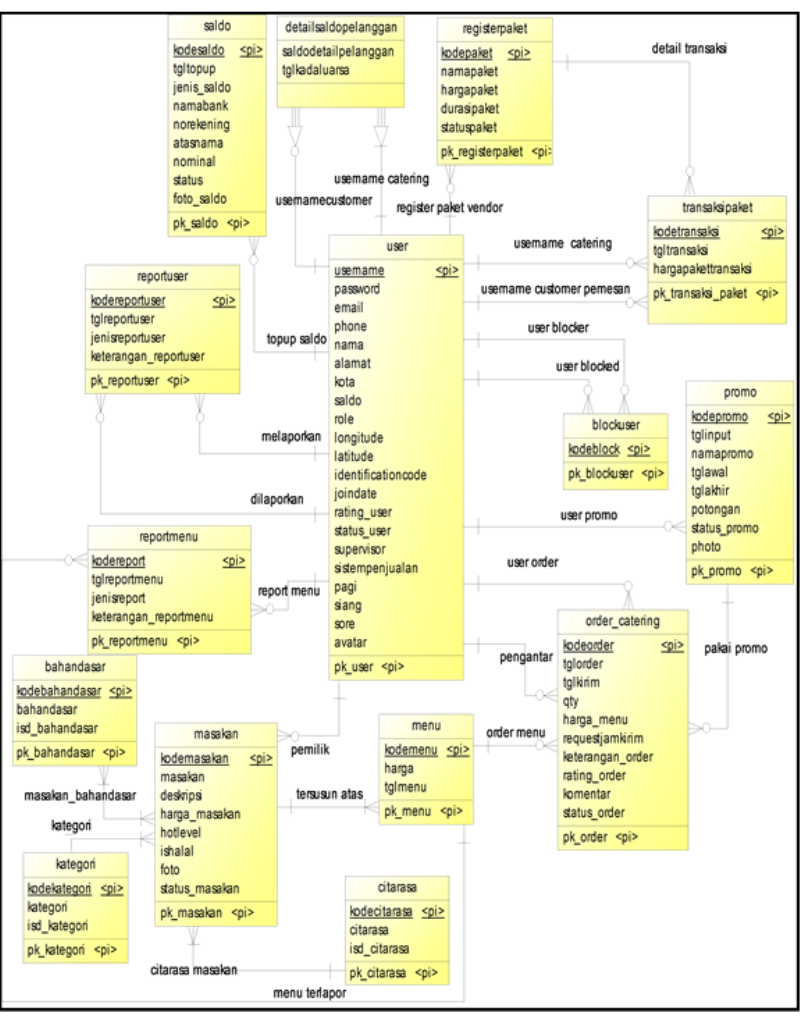

Gambar. 3. Arsitektur User Supervisor

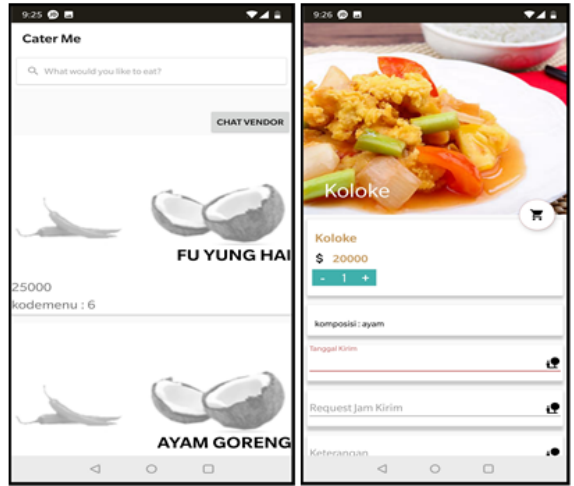

Gambar. 4. Desain Interface List Menu dan Detail Menu

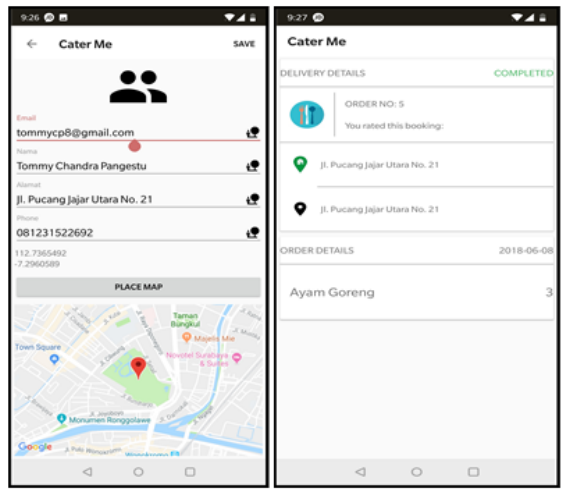

Gambar. 5. Desain Interface Setting Customer dan History Pemesanan

Gambar 5 tampilan halaman edit profile apabila user ingin mengganti data yang sudah terdaftar. Terdapat beberapa inputan, seperti email, nama, alamat, dan nomor telepon beserta lokasi pada map, beserta detil history pemesanan, Customer dapat melihat detail history transaksi- transaksi yang pernah dilakukan pada vendor-vendor catering serta melihat status pemesanannya.

\section{Algoritma}

Adapun algoritma yang dicontohkan adalah algoritma login tampak pada algoritma 1 .

\section{Algoritma 1. Algoritma Login}

01. User customer memilih catering

02. User customer memilih catering paket atau non paket

03. [Jika sistem penjualan non paket]

๑4. User customer memasukkan data berupa kuantiti, keterangan, tingkat kepedasan, tanggal kirim dan jam pengiriman

05. Customer menekan tombol purchase

06. Pengecekan apakah data yang dimasukkan sudah lengkap

07. [Jika valid]

๑8. Data dimasukkan ke dalam tabel order_catering

๑9. Memberikan notifikasi kepada vendor catering

10. [Jika tidak valid]

11. Menampilkan pesan error

12. [Jika sistem penjualan paket]

13. User customer memilih paket

14. User customer memilih menu

15. User customer memasukkan data berupa kuantiti, keterangan, tingkat kepedasan, tanggal kirim dan jam pengiriman

16. Pengecekan apakah data yang dimasukkan sudah lengkap

17. [Jika valid]

18. Data dimasukkan ke dalam tabel

19. emberikan notifikasi kepada vendor catering

20. [Jika tidak valid]

21. Menampilkan pesan error

Pada algoritma 1 merupakan algoritma customer yang ingin menambahkan transaksi baru. Customer memilih catering terlebih dahulu, jika customer memilih catering dengan sistem penjualan non paket maka user customer akan langsung diarahkan ke halaman memilih menu, jika user customer memilih catering dengan sistem penjualan paket maka customer akan diarahkan ke halaman pemilihan paket terlebih dahulu. Setelah selesai memilih paket maka customer akan diteruskan ke halaman pemilihan menu juga. Setelah customer selesai memilih menu maka akan diarahkan ke halaman menu detail, disini customer harus memasukkan data berupa kuantiti, keterangan, tingkat kepedasan, tanggal kirim dan jam pengiriman. Kemudian customer menekan tombol purchase diikuti dengan pengecekan data lengkap atau tidak. Jika sudah lengkap maka akan menyimpan ke tabel order_catering dan akan memberikan notifikasi kepada vendor catering yang bersangkutan. Jika data tidak lengkap maka akan menampilkan pesan error

\section{UJI COBA}

Pada tabel 1 merupakan uji coba untuk penambahan order transaksi pada aplikasi multi catering. Pertama user harus melakukan top up saldo dan memastikan jika saldo mencukupi untuk melakukan transaksi order yang diinginkan. User melakukan top up sesuai dengan nominal 
yang diinginkan dan memberikan notifikasi kepada admin. Top up saldo akan dicek dan diverifikasi oleh admin. Setelah admin melakukan verifikasi maka saldo user akan ditambahkan sesuai dengan nominal top up dan user akan mendapatkan notifikasi.

TABEL I

UJI COBA TRANSAKSI PEMESANAN

\begin{tabular}{|c|c|c|}
\hline Kasus Uji Coba & Hasil yang Diharapkan & Hasil Sebenarnya \\
\hline Top up saldo & $\begin{array}{l}\text { Top up saldo sesuai yang } \\
\text { diinginkan }\end{array}$ & Sesuai \\
\hline Insert top up saldo & $\begin{array}{l}\text { Data disimpan pada tabel } \\
\text { saldo dan memberikan } \\
\text { notifikasi kepada admin }\end{array}$ & Sesuai \\
\hline $\begin{array}{l}\text { Menunggu } \\
\text { verifikasi admin }\end{array}$ & $\begin{array}{l}\text { Admin melakukan } \\
\text { verifikasi }\end{array}$ & Sesuai \\
\hline $\begin{array}{l}\text { Admin melakukan } \\
\text { verifikasi }\end{array}$ & $\begin{array}{l}\text { Saldo user bertambah dan } \\
\text { user mendapatkan } \\
\text { notifikasi }\end{array}$ & Sesuai \\
\hline Memilih catering & $\begin{array}{l}\text { Memunculkan list catering } \\
\text { yang sudah bergabung } \\
\text { pada aplikasi multi } \\
\text { catering }\end{array}$ & Sesuai \\
\hline Memilih menu & $\begin{array}{l}\text { Memunculkan list menu } \\
\text { yang disediakan oleh } \\
\text { vendor catering }\end{array}$ & Sesuai \\
\hline $\begin{array}{l}\text { Saldo tidak cukup, } \\
\text { tanggal kirim } \\
\text { kosong, }\end{array}$ & Muncul pesan error & Sesuai \\
\hline $\begin{array}{l}\text { Saldo cukup, } \\
\text { Insert order baru }\end{array}$ & $\begin{array}{l}\text { Data disimpan pada tabel } \\
\text { order dan memberikan } \\
\text { notifikasi ke vendor } \\
\text { catering bersangkutan }\end{array}$ & Sesuai \\
\hline
\end{tabular}

User memilih catering dan akan memunculkan list catering yang telah bergabung pada aplikasi multi catering. User memilih menu maka akan memunculkan list menu yang disediakan oleh vendor catering. Jika user mengosongkan tanggal kirim maka akan memunculkan pesan error. Jika user mengosongkan request jam pengiriman maka akan memunculkan pesan error. Jika user mengosongkan keterangan maka akan memunculkan pesan error. Jika saldo tidak mencukupi maka akan memunculkan pesan error. Jika semua data sudah sesuai maka akan masuk ke dalam tabel order dan akan memberikan notifikasi kepihak vendor catering bersangkutan.

\section{A. Kuesioner}

Selain uji coba juga dilakukan kuesioner untuk mengetahui tanggapan user pengguna terhadap aplikasi. Uji coba dilakukan terhadap tiga jenis user yaitu vendor catering, customer dan pengantar. Pada subbab ini akan dijelaskan hasil dari kuesioner customer.
TABEL II

HASIL KUESIONER CUSTOMER

\begin{tabular}{|c|c|c|}
\hline No & Pertanyaan & Hasil \\
\hline 1 & $\begin{array}{l}\text { Apakah aplikasi } \\
\text { seperti ini perlu } \\
\text { untuk dibuat? }\end{array}$ & $\begin{array}{l}59.1 \% \text { responden menjawab sangat perlu, } \\
40.9 \% \text { responden menjawab perlu }\end{array}$ \\
\hline 2 & $\begin{array}{l}\text { Apakah sistem } \\
\text { registrasi customer } \\
\text { mudah dipahami? }\end{array}$ & $\begin{array}{l}68.2 \% \text { responden menjawab sangat mudah, } \\
27.3 \% \text { responden menjawab mudah, } \\
4.5 \% \text { responden menjawab sulit }\end{array}$ \\
\hline 3 & $\begin{array}{l}\text { Apakah } \\
\text { mekanisme top up } \\
\text { saldo mudah } \\
\text { dipahami? }\end{array}$ & $\begin{array}{l}59.1 \% \text { responden menjawab sangat mudah, } \\
40.9 \% \text { responden menjawab mudah }\end{array}$ \\
\hline 4 & $\begin{array}{l}\text { Apakah } \\
\text { mekanisme edit } \\
\text { profile mudah } \\
\text { dipahami? }\end{array}$ & $\begin{array}{l}68.2 \% \text { responden menjawab sangat mudah, } \\
31.8 \% \text { responden menjawab mudah }\end{array}$ \\
\hline 5 & $\begin{array}{l}\text { Apakah } \\
\text { mekanisme } \\
\text { mengubah } \\
\text { password mudah } \\
\text { dipahami? }\end{array}$ & $\begin{array}{l}59.1 \% \text { responden menjawab sangat mudah, } \\
40.9 \% \text { responden menjawab mudah }\end{array}$ \\
\hline 6 & $\begin{array}{l}\text { Apakah } \\
\text { mekanisme order } \\
\text { menu dan paket } \\
\text { catering mudah } \\
\text { dipahami? }\end{array}$ & $\begin{array}{l}68.2 \% \text { responden menjawab sangat mudah, } \\
31.8 \% \text { responden menjawab mudah }\end{array}$ \\
\hline 7 & $\begin{array}{l}\text { Apakah tampilan } \\
\text { pesanan yang } \\
\text { sedang aktif } \\
\text { mudah dipahami? }\end{array}$ & $\begin{array}{l}59.1 \% \text { responden menjawab sangat mudah, } \\
36.4 \% \text { responden menjawab mudah, } \\
4.5 \% \text { responden menjawab sulit }\end{array}$ \\
\hline 8 & $\begin{array}{l}\text { Apakah tampilan } \\
\text { aplikasi Cater Me } \\
\text { menarik untuk } \\
\text { dilihat? }\end{array}$ & $\begin{array}{l}59.1 \% \text { responden menjawab sangat } \\
\text { menarik, } \\
31.8 \% \text { responden menjawab menarik, } \\
9.1 \% \text { responden menjawab kurang menarik }\end{array}$ \\
\hline 9 & $\begin{array}{l}\text { Apakah tampilan } \\
\text { history pemesanan } \\
\text { sudah memberikan } \\
\text { pesan informatif? }\end{array}$ & $\begin{array}{l}50 \% \text { responden menjawab sangat } \\
\text { informatif, } \\
40.9 \% \text { responden menjawab informatif, } \\
9.1 \% \text { responden menjawab kurang } \\
\text { informatif }\end{array}$ \\
\hline 10 & $\begin{array}{l}\text { Apakah alur } \\
\text { system mudah } \\
\text { dipahami? }\end{array}$ & $\begin{array}{l}63.6 \% \text { responden menjawab sangat mudah, } \\
18.2 \% \text { responden menjawab mudah, } \\
18.2 \% \text { responden menjawab sedikit sulit }\end{array}$ \\
\hline
\end{tabular}

Pada uji coba ini melibatkan sejumlah 22 (dua puluh dua) Customer. Pertanyaan terhadap pemesanan pada multi catering dapat dilihat pada tabel 2. Rangkuman hasil kuesioner dilaporkan dalam bentuk presentase terhadap setiap opsi jawaban yang terangkum pada kolom ketiga. Hasil prosentase diambil dari jumlah pemilih opsi jawaban tersebut dibagi dengan total customer yang berpartisipasi.

\section{KESIMPULAN}

Kesimpulan yang didapatkan pada selama pembuatan aplikasi antara lain:

- Memudahkan customer dalam membandingkan harga paket dan menu yang dipilih dari berbagai vendor catering.

- Firebase Realtime database sangat membantu dalam hal penyimpanan dan pengaksesan data yang realtime, khususnya chatting dan notifikasi.

- Google Sign In dan Facebook dan aplikasi Android yang dikembangkan.

- Library Ksoap2 memudahkan aplikasi android dalam hal pengaksesan service yang berada di server. 


\section{UCAPAN TERIMA KASIH / ACKNOLEDGMENT}

Penulis mengucapkan terima kasih Permata Catering yang mendukung penelitian penulis sehingga penelitian dapat berjalan hingga selesai.

\section{DAFTAR PUSTAKA}

[1] Joseph S. Valacich, Joey F. George, Jeffrey A. Hoffer, "Essential of Systems Analysis and Design 5 ed,", 2012, Pearson.

[2] Neil Smyth, "Firebase Essentials," Create Space Independent Publishing, 2016.

[3] Neil Smyth, "Android Studio Development Essentials," Create Space Independent Publishing, 2017.

[4] Paperback, "Google Android Firebase: Learning the Basics.," USA, Bill Stonehem.

[5] Wei Meng Lee, "Beginning Android Application Development,", Wrox, 2011.

Tommy Chandra Pangestu S1 Informatika STTS pada tahun 2018. Minat penelitiannya adalah Technopreneurship.

Amelia Alexandra P. W lahir di Surabaya, Indonesia, pada tahun 1991. Dia menyelesaikan studi S1 di program studi Informatika STTS pada tahun 2013. Minat penelitiannya adalah Mobile Computing dan Data Mining.

Tjwanda Putera Gunawan lahir di Surabaya, Indonesia, pada tahun 1964. Dia menyelesaikan studi S1 di program studi Elektro STTS pada tahun 1989. Bejo menyelesaikan studi masternya pada jurusan Matematika UNESA pada tahun 2005. Minat penelitiannya adalah Mathematic Engineering. 